\title{
Research on the Impact of the Coronavirus Disease 2019 (COVID-19) Pandemic on the Global Trade Economy Based on Big Data Analysis
}

\author{
Jianfei Li, School of Marxism, Xi'an Jiaotong University, Xi'an, China \\ Juxing Li, School of Journalism and New Media, Xi'an Jiaotong University, Xi'an, China \\ Jin Ji, School of Marxism, Xi' an Jiaotong University, Xi'an, China \\ Shengjun Meng, School of Journalism and New Media, Xi'an Jiaotong University, Xi'an, China
}

\begin{abstract}
The coronavirus disease 2019 (COVID-19) pandemic that began in early 2020 quickly spread globally, bringing unprecedented shocks to many countries and even the global trade economy. Big data is the main feature of the internet era. It has transformed the industrial development pattern of modern society and has now flourished in the field of trade economy; therefore, it is of great significance to apply the big data analysis technology to study the impact of the COVID-19 pandemic on the global trade economy. On the basis of summarizing and analyzing previous research works, this paper expounded the research status and significance of the impact of the COVID-19 pandemic on the global trade economy and elaborated the development background. The study results of this paper provide a reference for further studies on the impact of the impact of the COVID-19 pandemic on the global trade economy based on big data analysis.
\end{abstract}

\section{KEYWORDS}

Big Data Analysis, COVID-19 Pandemic, Epidemic Impact, Global Trade Economy

\section{INTRODUCTION}

The global pandemic of the coronavirus disease 2019 (COVID-19) has had a broad and far-reaching impact on the world's economic development. It will not only re-deconstruct the core concepts and basic connotations of economic globalization, but also reshape the ecological system of the world economy, and promote a fundamental change in the global governance system (Jones, 2020). Based on past experience, the spread of the epidemic will have an impact on the normal operation of the economy, and then it will evolve into an important exogenous factor affecting economic growth. The previous outbreaks of the epidemic will have a certain impact on the place where the epidemic broke out, and even the development of the world economy (Halawani et al., 2020). The COVID-19 epidemic will accelerate the world's multi-polarization trend and regional division of labor will accelerate the replacement of global division of labor. As an infectious disease crisis, the COVID-19 epidemic is a typical global public crisis, whose spread exceeds expectations and has a huge impact on public

DOI: 10.4018/JOEUC.20211101.oa14

This article published as an Open Access article distributed under the terms of the Creative Commons Attribution License (http://creativecommons.org/licenses/by/4.0/) which permits unrestricted use, distribution, and production in any medium, provided the author of the original work and original publication source are properly credited. 
health, economic development, and social stability (Matthijs, 2020). Public crises have important characteristics such as suddenness and urgency, uncertainty, sociality, and non-procedural decisionmaking, which may cause major damage to the smooth operation of the economy and society, and even cause global shocks. The economic analysis of public crises and economic reconstruction measures are important research tasks for academic and policy circles (Wei \& Ho, 2019).

The big data analysis technology can help users quickly and efficiently obtain their required information in massive network data. A big data classification system needs to be designed to help users quickly and effectively obtain the required information in a large amount of network data. Since the outbreak of the COVID-19 epidemic, international economic organizations, especially international financial institutions, have been paying attention to the impact of the development of the epidemic on the economy and many international financial institutions were born in crises and have experienced many crises (Cunningham \& Scarlata, 2020). It not only serves as a financial safety net or financial support, but first is to make predictions about the impact on the global economy, and secondly, it is necessary for the countries concerned. They should put forward country-specific policies and cooperation policies, and finally implement them to truly provide financial support to vulnerable countries affected by the epidemic (Evenett, 2020). With large-scale shutdowns and production shutdowns, cross-border and even domestic logistics are hindered, production enterprises are facing unprecedented challenges in production, transportation and employment, especially in cross-border manufacturing (Khan et al., 2017). With the expansion of the impact of the epidemic, most companies have to enter a short period of dormancy and short-term gaps have appeared in the global supply chain. The expansion of the global supply chain network has seriously affected the continuation of integrated mass production in stable development can easily lead to the shrinking of global trade and the closure of production enterprises (Cacciapaglia et al., 2020).

On the basis of summarizing and analyzing previous research works, this paper, expounded the research status and significance of the impact of the COVID-19 epidemic on the global trade economy, elaborated the development background, current status and future challenges of big data analysis technology, introduced the methods and principles of economic growth path and production factor combination method, analyzed the impact of the COVID-19 epidemic on the global production chain process and trade development version, explored the impact of the COVID-19 epidemic on global supply chain security and international financial market crisis, discussed the economic policy support system and the economic globalization pattern in the post-epidemic era. The study results of this paper provide a reference for further researches on the impact of the impact of the COVID-19 epidemic on the global trade economy based on big data analysis. The detailed chapters are arranged as follows: Section 2 introduces the methods and principles of economic growth path and production factor combination method; Section 3 analyzes the impact of the COVID-19 epidemic on the world economic situation; Section 4 explores the impact of the COVID-19 epidemic on the global industries and markets; Section 5 the economic policy support system and the economic globalization pattern in the post-epidemic era; Section 6 is conclusion.

\section{METHODS AND PRINCIPLES}

\subsection{Economic Growth Path}

The production department determines the utilization of intermediate inputs and main production factors according to cost minimization, and determines the output distribution between the domestic market and the international market according to profit maximization. The nested production function is used to describe the input structure used by each production department. The top of the input structure, intermediate inputs, main production factors and other inputs are given by the following formula: 
$P(i)=k\left[\frac{a(i)}{A}-\frac{b(i)}{B}\right]$

Where $A$ is the industry; $B$ is the product; $a(i)$ is the source of sector $i ; b(i)$ is the output of sector $i ; k$ is the intermediate input used by sector $i$.

It is supposed that the economy and society use labor and capital for production at a certain technological level, therefore the production function is:

$$
H_{i}=\gamma \cdot \frac{F(x, y)}{P(i)}
$$

Where $H_{i}$ is the total output of department $i ; x$ and $y$ are the input labor and capital respectively; $\gamma$ is the total factor productivity; $F$ is the total input of social production factors.

It is assumed that the impact of the COVID-19 epidemic on labor input in region $i$ is $N_{i}$, and the impact on the amount of capital input is $M_{i}$, the impact of the COVID-19 epidemic on the economic growth of region $i$ can be expressed as:

$$
\ln Q_{i}=\alpha \cdot \ln M_{i}+\beta \cdot \ln N_{i}
$$

Where $\ln Q_{i}$ is the total economic output of sector $i$; $\ln M_{i}$ is the total social labor input of sector $i$; $\ln N_{i}$ is the social capital input of sector $i$, which can be expressed by the fixed asset input of the whole society; $\alpha$ and $\beta$ are COVID-19 epidemic-influenced coefficient coefficients.

The production of intermediate products in different industries in different countries has different productivity. Here $W_{i j}$ is defined as the efficiency of producing intermediate products $w_{i}$ in industry $i$ in country $n$, and the production function of $w_{i}$ is as follows:

$$
W_{i j}=\sum_{i, j=1}^{n}\left(\mu \frac{S_{j}}{w_{i}}-\tau \frac{T_{j}}{w_{i}}\right)
$$

Where $S_{j}$ is the set of intermediate inputs from industry $j$ required for the production of $w_{i}$ in industry $i ; \mu$ and $\tau$ are the share of the intermediate input from industries $i$ and $j$ in the total input $n$ to produce $w_{i} ; T_{j}$ is the total input from the input share of labor. Because the production of intermediate goods is constant return to scale, and all markets are perfectly competitive markets, the domestic price per unit is $E_{i}$, and its expression is:

$$
E_{i}=\int_{i=1}^{n}\left[Q_{i}\left(x_{i}\right)+P_{i}\left(y_{i}\right)\right]
$$

Where $x_{i}$ and $y_{i}$ are the set prices of the intermediate input and output of industry $i$, respectively. It transforms and expands the traditional input-output model to quantify the share of added value contained in the final consumer goods and intermediate inputs produced by various industries in a country, as well as the share of intermediate inputs from other industries. 


\subsection{Production Factor Combination}

It is assumed that there are $n$ countries, and $x_{i j}(i=1,2, \ldots, n ; j=1,2, \ldots, n)$ is the volume of trade from the $i$-th country to the $j$-th country; $X_{i j}$ is the $j$-th for the country's import volume from the $i$-th country, then the trade links between countries can be represented by the following matrix $\boldsymbol{X}$ :

$$
\boldsymbol{X}=\left(\frac{x_{0 j}}{\alpha_{i j}}-\frac{x_{i 0}}{\beta_{i j}}-\frac{x_{i j}}{\gamma_{i j}}\right)^{2}
$$

Where $\alpha_{i j}, \beta_{i}$ and $\gamma_{i j}$ are COVID-19 epidemic-influenced coefficient coefficients of trade volume $x_{0 j}, x_{i 0}$ and $x_{i j}$ from the $i$-th country to the $j$-th country. The sum of the elements in the $i$-th row of the matrix is the total export trade value of the $i$-th country to other countries, the sum of the elements in the $i$-th column is the total import trade value $A_{i}$ of the $i$-th country from other countries, and the sum of the elements in the $i$-th column is the total import trade volume $B_{i}$ of the $i$-th country from other countries, the difference between the two is the balance of the $i$-th country's import and export trade in the balance of payments:

$$
B_{i}-A_{i}=\sum_{i=1}^{n} \boldsymbol{X}_{i j}-\sum_{j=1}^{n} \boldsymbol{X}_{j i}
$$

In the year of the outbreak of the COVID-19 epidemic, the government's investment in epidemic prevention funds and other donations in epidemic prevention funds were put into use in the same year, the impact of the COVID-19 epidemic on the amount of capital investment in $i$ region $\Phi_{i}$ can be expressed as:

$$
\Phi_{i}=B_{i}+\lambda A_{i}
$$

In this formula, $\lambda$ is the ratio of the regional government's investment in epidemic prevention to the regional donation of funds. Calculating the total input produced by industry $i$ in country $n$ from the intermediate input share as $E_{i}$, and also defining $F_{i}$ as the share of the total input produced by industry $i$ in country $n$ from the intermediate input in country $i$, the calculation formula for the difference value $\Pi$ is:

$$
\Pi=\left|E_{i}-F_{i}\right|=\sqrt{\sum_{i=1}^{n}\left[\frac{t\left(E_{i}-F_{i}\right)}{u\left(E_{i}+F_{i}\right)}\right]^{2}}
$$

Where $t$ is the total value-added of the $i$-th industry in country $n ; u$ is the input share of labor in the total input produced by industry $i$ in country $n$.

It is supposed that the intermediate input set producer in the $n$ country $i$ industry buys intermediate goods $w_{i}$ at the lowest price in the world, so as to produce the intermediate input set at the lowest cost:

$\delta_{v}(i)=-\frac{\Pi_{i}}{w_{i}} \cdot \frac{\Phi_{i}}{w_{i}}$ 
Where $\delta_{v}(i)$ is the demand for the intermediate input manufacturer in the $i$-th industry in country $n$ to purchase $w_{i}$ from the lowest cost supplier for production. Under the premise of ensuring the normal fulfilments of existing orders, actively conduct research on domestic and foreign market demands, and adjust categories and quantities according to market demand in a timely manner to promote the transformation of enterprise market demand in response to future market demand structure adjustments.

\section{IMPACT ON THE WORLD ECONOMIC SITUATION}

\subsection{Global Production Chain Process}

The capital chain refers to the basic circulation formed by corporate funds in maintaining the normal production and operation activities of the enterprise, and is the blood of the corporate flow. The outbreak of the COVID-19 epidemic has affected the production and sales activities of export-oriented agricultural enterprises and the trade restriction measures of some countries have greatly hindered the export of products. In addition, the common settlement methods in foreign trade exports are diverse, including documentary collection, remittance, etc. In most cases, exporters cannot collect the full payment before delivery of the goods, and agricultural enterprises that encounter difficulties in transportation and cannot deliver are naturally unable to obtain the payment. Although stringent control measures are very effective in preventing and controlling the epidemic, they will make society lack of living materials and are not conducive to the operation of the national economy (Sidhu et al., 2020). With the passage of time, the cash flow of the enterprise will gradually become tense, or even exhausted, leading to the break of the capital chain. Due to the production stagnation and traffic congestion caused by the epidemic, these companies will face the dilemma of difficulty in delivering goods. Once they fail to perform the contract, they may be liable for breach of contract and this is undoubtedly a huge challenge for agricultural enterprises that are already short of funds. Moreover, in foreign trade, honesty is an indispensable quality of an enterprise and the breach of contract brings not only short-term profit loss to export-oriented enterprises, but also affects the company's reputation.

Facing the huge impact of the COVID-19 epidemic on social life and economic development, the overall planning of epidemic prevention and development must first play the leading role of macro-control in the market economy. The combination of market economy and macroeconomic control is an important system for coping with economic calming cyclical or occasional shocks and maintaining stable and rapid economic development. Through the concerted efforts of monetary, credit, fiscal and other supporting policies, the government's macro-control has effectively solved the urgent problems of debt repayment, capital turnover and expanded financing faced by enterprises in resuming work and production. In terms of credit policy, provide more credit loans and medium and long-term loans to small and micro enterprises, private enterprises and key manufacturing enterprises, and support financial institutions to issue bonds, asset-backed securities, and short-term financing bills. The economic impact model of COVID-19 epidemic at its different stages is shown in Figure 1. The policies give full play to the decisive role of the market in the allocation of resources, which give full play to the advantages of the market's sensitivity to information, flexible adjustment methods, and obvious incentive effects to improve the vitality and efficiency of economic development. The primary distribution not only uses the quantity and quality of labor as the basis for individuals to get remuneration, the more you work, the more you get, but also the income distribution based on the ownership of production factors, allowing labor, capital, land, knowledge, technology, management, and data based on contribution (Singh \& Agrawal, 2018).

In addition to responding to the quiet period of tourism during the epidemic, major online business platforms will also face a recovery period just after the epidemic and a tourism rebound period after the epidemic. All of the above tests the event processing capabilities, response capabilities, organization and coordination capabilities, and platform resource coordination capabilities of the online business platform. The epidemic is a severe test for the platform, and how to deal with and grasp the rebound in business demand after the epidemic will bring a new round of challenges to 
Figure 1. Economic impact model of COVID-19 epidemic at its different stages

\begin{tabular}{|c|c|c|}
\hline Epidemic stage & Economic impact & Alleviation measures \\
\hline Post-epidemic era & $\begin{array}{l}\text { Continued downturn } \\
\text { of global trade economy }\end{array}$ & $\begin{array}{l}\text { The slow recovery of } \\
\text { global economic trade }\end{array}$ \\
\hline $\begin{array}{c}\text { Second wave of } \\
\text { COVID-19 epidemic }\end{array}$ & $\begin{array}{l}\text { Shrinking of transnational } \\
\text { economy and trade }\end{array}$ & $\begin{array}{l}\text { Emergency fund } \\
\text { and package plan }\end{array}$ \\
\hline $\begin{array}{l}\text { First wave of } \\
\text { COVID-19 epidemic }\end{array}$ & $\begin{array}{l}\text { Financial dilemma of } \\
\text { small and micro enterprises }\end{array}$ & $\begin{array}{l}\text { Debt relief and } \\
\text { relief agreements }\end{array}$ \\
\hline
\end{tabular}

the platform. The epidemic will inevitably cause delays in shipments or disrupt cross-border sellers' replenishment plans, and some cross-border sellers may experience a crisis of out of stock (Ahluwalia \& Merhi, 2020). Online education resources are rich, free from space constraints, and more flexible and online education has a large amount of learning data. Through reasonable processing and analysis, it can more accurately understand and match the needs of students. Online education attracts more and more users with its high-efficiency and strong interaction characteristics, and it has become a form of education generally accepted by users. Merchants need a socialized customer management system to allow merchants and customers to establish a strong relationship and realize shopping anytime, anywhere. The epidemic has a huge impact on offline physical businesses, and face-to-face consumption is difficult to carry out in the short term, but the model of online platforms and offline pre-positioning will increase the number of orders.

\subsection{Trade Development Version}

The COVID-19 epidemic is a major external shock that has affected the trend of the world economic structure since economic globalization. On the one hand, the epidemic may cause the world to experience the worst economic recession since the great depression; on the other hand, the impact of the epidemic is intensifying the structural reshuffle between countries, accelerating the localization, regionalization, and decentralization of the global supply chain and industrial chain. The COVID-19 epidemic will accelerate the world's multi-polarization trend and regional division of labor will accelerate the replacement of global division of labor. The signing and implementation of some super-large regional trade arrangements will further strengthen the regionalization of the three major sectors (Fabisiak, 2018). The reconstruction of the global industrial chain in the post-epidemic era is inevitable and avoids appearing in a global division of labor, an economic globalization in transition. At present, the government adopts strong measures, not only to avoid the spread of the epidemic, but also to eliminate the virus in the shortest time, so as to reduce the impact on society and the economy. The time to resume work in the future obviously depends on the situation of epidemic control. If the epidemic is effectively controlled, work may resume in a relatively short time. If the epidemic control is difficult, the time for resumption of work will continue to be delayed and the degree of influence will also be differences. Figure 2 shows the impact model of COVID-19 epidemic for trade economy based on big data.

In many countries affected by the epidemic, production has slowed down or even stopped, the global industrial chain and supply chain have been blocked or partially broken and external demand has shrunk further, putting tremendous pressure on foreign trade companies. It is particularly noteworthy that due to the fragile division of labor in the global industrial chain, the epidemic may lead to a strategic contraction of the international division of labor (Celik et al., 2020). Many countries may face the risk of reshuffling their positions in the global supply chain and industrial chain. Some countries attempting to use the pretext of preventing and controlling the epidemic has increased the possibility of inciting new trade disputes. Anti-globalization and the rise of trade protectionism will 
Figure 2. Impact model of COVID-19 epidemic for trade economy based on big data

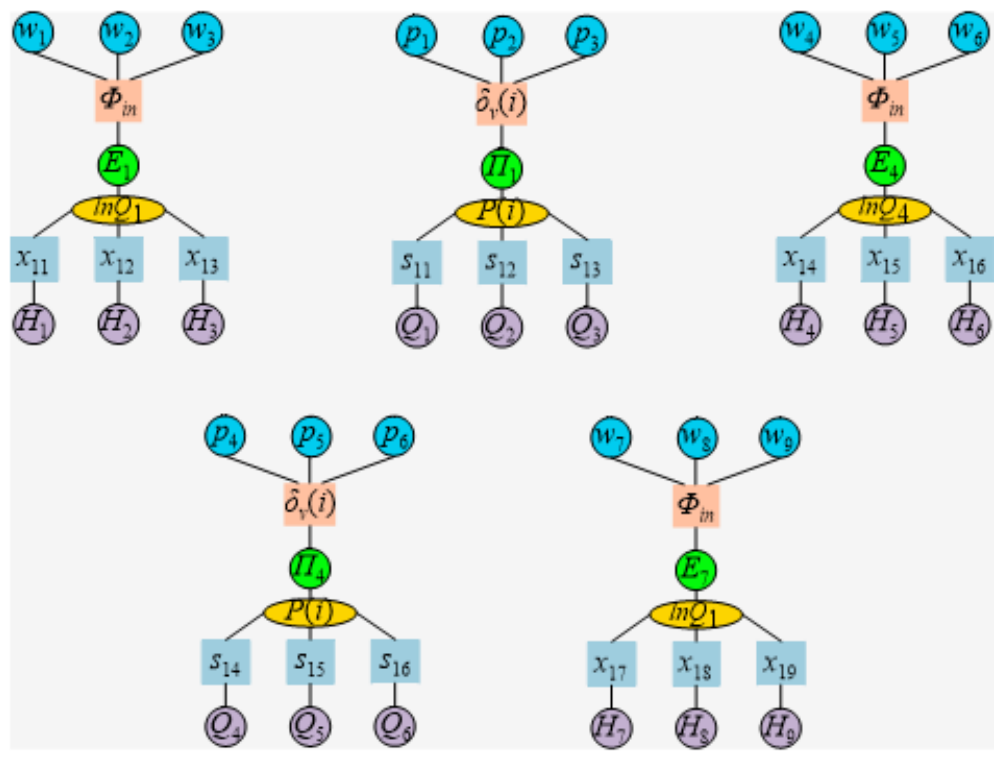

all lead to long-term pressure on my country's external economic environment. Supply-side shocks are mainly for the import of raw materials, fuels, energy, technology and other products, services, and other intermediate products (Table 1). Due to various export restrictions, production restrictions, and personnel isolation measures adopted by exporting countries, logistics stagnation and imports by foreign trade companies are blocked. They affects the production of domestic enterprises, the efficiency of enterprise capacity utilization decreases, and operating costs increase; while demand-side shocks mainly occur in foreign trade companies with relatively large sales in overseas markets. The epidemic directly leads to shrinking overseas demand, reducing or transferring orders, and customers drain, inventory backlog, and decline in corporate asset turnover.

In terms of macro analysis, international financial institutions have made timely and detailed calculations on the impact of the COVID-19 epidemic on the economy, and both supply and demand will be hit hard. In terms of policy recommendations, international financial institutions all recommend loose policies, including loose monetary policies to prevent short-term financial market fluctuations, loose fiscal policies to increase aggregate demand, and smooth information and international cooperation are also very important. In terms of financial support, with the spread of the epidemic, financial institutions provide financial support through donations, loans, funds, debt relief, package plans, etc. The initial funds are mainly used for medical infrastructure, and the latter

Table 1. Macroeconomic impact of COVID-19 epidemic

\begin{tabular}{|c|c|c|}
\hline Item variation & Optimistic situation & Pessimistic situation \\
\hline Investment & -0.248 & -1.482 \\
\hline Importation & -1.384 & -2.113 \\
\hline Exportation & -0.981 & -1.863 \\
\hline Consumption & -1.675 & -2.447 \\
\hline Consumer price index & -0.035 & -1.037 \\
\hline
\end{tabular}


funds are used more for rescue the economy affected by the epidemic. In this response, international financial institutions have generally learned from previous crisis response experience and provided rapid financial support to restore confidence and stabilize financial markets. At the same time, they no longer attach austerity policies, but promote long-term structural economic policies to promote long-term economic recovery will save the losses caused by the impact of the epidemic. Of course, the epidemic is still developing, and the analysis of international financial institutions is also being updated. Based on sufficient data and high-level economists, the analysis of international financial institutions can provide a valuable reference for governments and economic entities (Raposo, 2020).

\section{IMPACT ON INDUSTRIES AND MARKETS}

\subsection{Global Supply Chain Security}

The rapid spread of the COVID-19 epidemic in countries around the world has a major impact on the security of the global supply chain. Countries should strengthen trade cooperation and customs cooperation and consultation, resume international routes as soon as possible under the premise of effective epidemic prevention and control, remove customs restrictions, suspensions, suspensions, rejections, and tariff increases of relevant trading countries as soon as possible, and open up crossborder logistics channels barriers to ensure the smooth flow of cross-border supply chains (Figure 3 ). Countries should strengthen the communication and cooperation of capacity supply and demand information; they promote the establishment of a multilateral cooperation framework for supply chain capacity coordination under epidemic conditions (Bhoring, 2020). They actively promote the construction of a global supply chain security governance system, and explore corresponding governance mechanisms, decision-making systems, governance structures and governance models. Countries in the world should jointly promote trade liberalization, further strengthen the free trade cooperation between countries, promote the efficient flow of global people, business, logistics, capital, and information, and build a higher level of open regional industrial chain, technological innovation chain and global value chain. Countries should take the emergency response capability of unconventional emergencies supply chain as an important indicator to assess the maturity of the supply chain of enterprises, strengthen the scenario deduction of emergencies, and promote the emergency reform of enterprises in the aspects of supply chain technology, organizational philosophy, processes, and cooperation methods.

External trade restrictions and domestic closure measures have resulted in restrictions on key land, air and sea transportation routes, delays in resumption of work, and even suspension of production, which will have a serious negative impact on manufacturing production and its import and export trade for a period of time. But overall, compared to external suspensions, immigration controls, and trade restrictions, what needs more attention is the progress of domestic epidemic control and resumption of production. On the one hand, the degree of epidemic control is the determining factor and suspension and immigration arrangements are also dynamically adjusted as the epidemic progresses. On the other hand, it is not external demand that currently has a greater impact on trade and shipping, but domestic resumption of work and production and supply. The epidemic has delayed the recovery of production and foreign trade, resulting in reduced demand for shipping and shipping, and a corresponding passive reduction in the volume of ships and containers. At present, the resumption rate of most companies is not high. Information released by the state council's joint prevention and control mechanism meeting shows that from the perspective of business entities, the resumption of work and production of enterprises above designated size, upstream industries. The capital and technology-intensive enterprises is relatively fast, while downstream industries, laborintensive enterprises and small and medium-sized enterprises have resumed work and production. In some areas, enterprises need to have the relevant prevention and control equipment and measures 


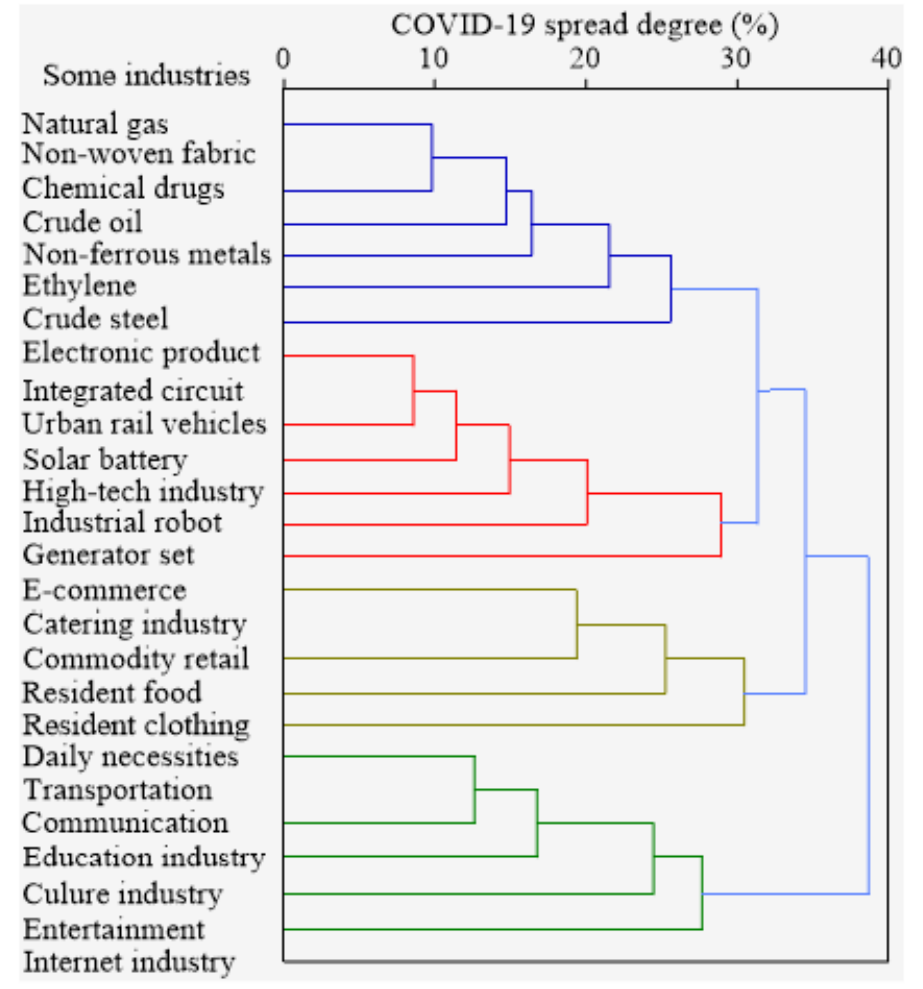

reviewed by the government department, and the relevant government department has issued a work permit before they can resume production (Kim, 2019).

The current golden age of digital economy development, the maturity and application of digital technologies such as artificial intelligence, big data, and cloud computing have greatly promoted profound changes in all aspects of the social economy. In the context of the global pandemic of the COVID-19 epidemic, international trade through cross-border e-commerce and even global digital trade have obvious practical significance (McEwan et al., 2020). Epidemic prevention crisis management has three characteristics: global public goods, professional international cooperation, and the driving force of global integration. First of all, this kind of crisis has the characteristics of the indivisibility of the utility of public goods, the non-competitive and non-exclusive characteristics of consumption. Indivisibility means the need to provide the world with epidemic prevention crisis management with common interests or joint consumption characteristics. The so-called noncompetitive nature of consumption is mainly manifested in the fact that no country can exclusively enjoy the benefits of epidemic prevention and crisis management. The non-exclusiveness means that its influence has surpassed a certain country or region and the management of epidemic prevention crisis requires the assistance of professional international cooperation. With the ever-increasing global connections, no country can deal with threats such as infectious diseases alone. The market demand and lack of consumer confidence in the foreign trade import and export industry have affected the growth of market demand, resulting in the reduction of some orders and even the cancellation of original orders. 
Figure 4. Lose factors of global supply chain security (a) and production chian (b) with different COVID-19 spread degree
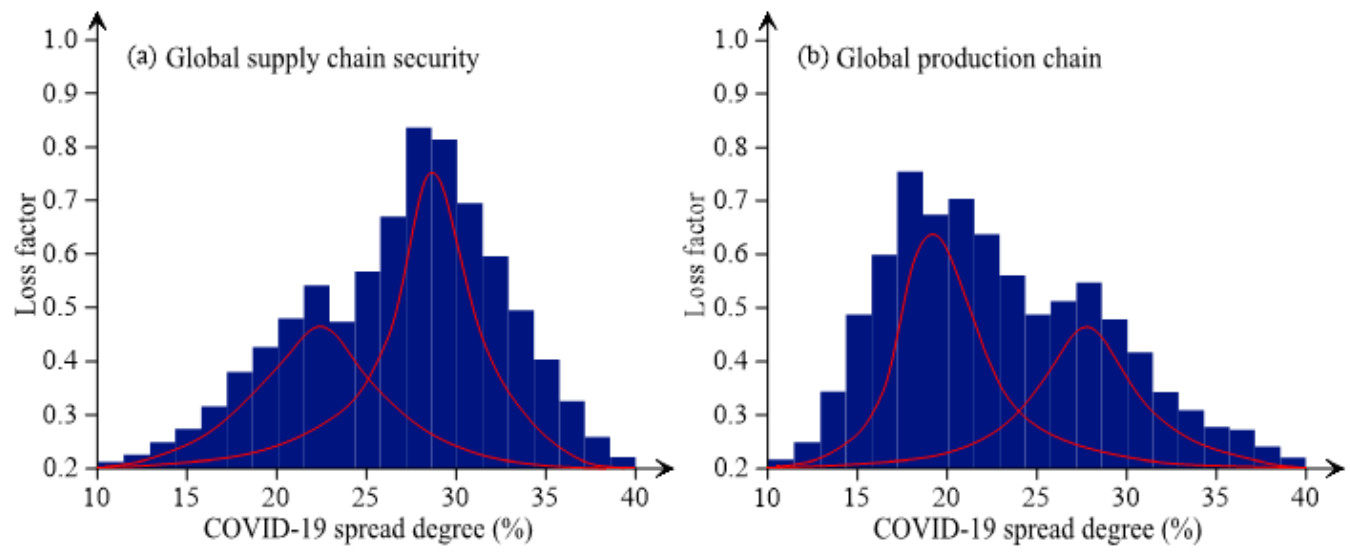

\subsection{International Financial Market Crisis}

This COVID-19 epidemic has caused regional division, stagnation of logistics, and personnel staying or isolation, which takes time for such a large supply chain to return to a normal state, and the currently stagnant supply chain, may appear after large-scale construction starts and imbalance will have a negative impact on project cost and efficiency. Individuals, families, companies, cities, and society are all facing this comprehensive test to test our ability, conduct, and coping strategies. Enterprises should think about how each position and each team organizes the various tasks of the project operation. In addition to the work within the scope of the project, they should also think about the coordination with various related parties, the complex supply chain, the implementation of mass production tasks, and the project supervision, project measurement and payment, a large number of people, logistics, and equipment are all completed on the basis of great collaboration. Enterprises should think about how each position and each team organizes the various tasks of the project operation (Wei, 2020). For global supply chain security, there are two loss factor peaks with about 0.48 at $23 \%$ COVID-19 spread degree and about 0.75 at $28 \%$, respectively; for global production chain, there are also two loss factor peaks with about 0.65 at 19\% COVID-19 spread degree and about 0.48 at $27 \%$, respectively (Figure 4). The supervision of the project, the project measurement, personals, logistics, and equipment are all completed on the basis of great collaboration.

The current golden age of the development of the digital economy, the maturity and application of digital technologies such as artificial intelligence and big data have greatly promoted profound changes in all aspects of the social economy. As an important part of the digital economy, cross-border e-commerce can break through the limitations of time and space, meet the increasingly individual needs of consumers, and promote the rapid transformation of international trade with its unique advantages (Figure 5). As the development of cross-border e-commerce becomes more and more mature, its phased characteristics of digitization are becoming more and more significant, and will achieve qualitative changes under the accumulation of continuous quantitative changes, and iterate into global digital trade. In the context of the global pandemic of the COVID-19 epidemic, international trade through cross-border e-commerce and even global digital trade have obvious practical significance (Derevyankina \& Yankovskaya, 2020). In the short term, cross-border e-commerce can help meet the cross-border shopping needs of domestic consumers, help domestic export companies match the needs of overseas markets, and restore the normal operation of all links in the trade chain. In the long run, global digital trade will help to improve the operational efficiency of the entire chain of crossborder trade, to cultivate the advantages of enterprises to participate in international competition, and to enhance the foreign trade industry's ability to respond to various risks such as the epidemic. 


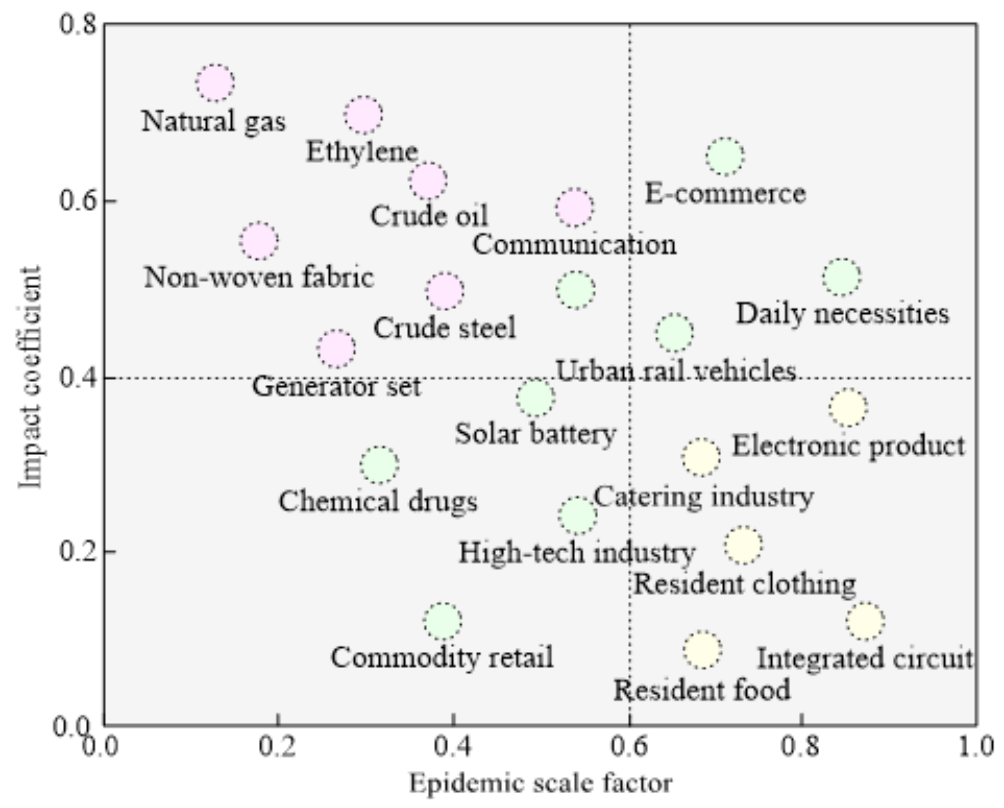

The global pandemic of the COVID-19 epidemic has profoundly affected the trading of various transaction entities in international trade, and brought opportunities for international trade iteration.

With the rise and development of small and medium-sized enterprises in the foreign trade import and export industry in recent years, the proportion of small and medium-sized enterprises in the foreign trade industry has increased, and the most severely affected by this epidemic are also small and medium-sized enterprises. In this regard, various departments and localities have also given great support to small and medium-sized enterprises by increasing tax and fee reductions to reduce the burden on business operations and providing corresponding financial support to small and mediumsized enterprises to help ensure the continuous and stable supply of the corporate capital chain. In addition, they optimize the management of small and medium-sized enterprises serving the foreign trade industry by governments at all levels, not only providing management solutions for enterprises, but also providing technical support for enterprises (Hart \& Halden, 2020). Faced with the current actual market environment, foreign trade companies should review the current situation, adjust their production plans in a timely manner, strengthen control over the implementation of their production plans, and ensure that upstream supply and downstream sales are not affected. They make full use of the policy preferences given by the government to ensure the continuous supply of the capital chain. Under the premise of ensuring the normal work of existing orders, actively conduct research on domestic and foreign market demand, and adjust categories and quantities in time according to market demand to promote the transformation of enterprise market demand to respond to future market demand structure adjustments.

\section{DISCUSSIONS}

\subsection{Economic Policy Support System}

In the practice of global epidemic prevention and control, governments of various countries have taken a large number of measures to deal with the cross-border spread of the COVID-19 epidemic, 
Figure 6. Impact coefficients of three typical industries in global production chain process (a), trade development version (b), global supply chain security (c) and international financial market crisis (d)
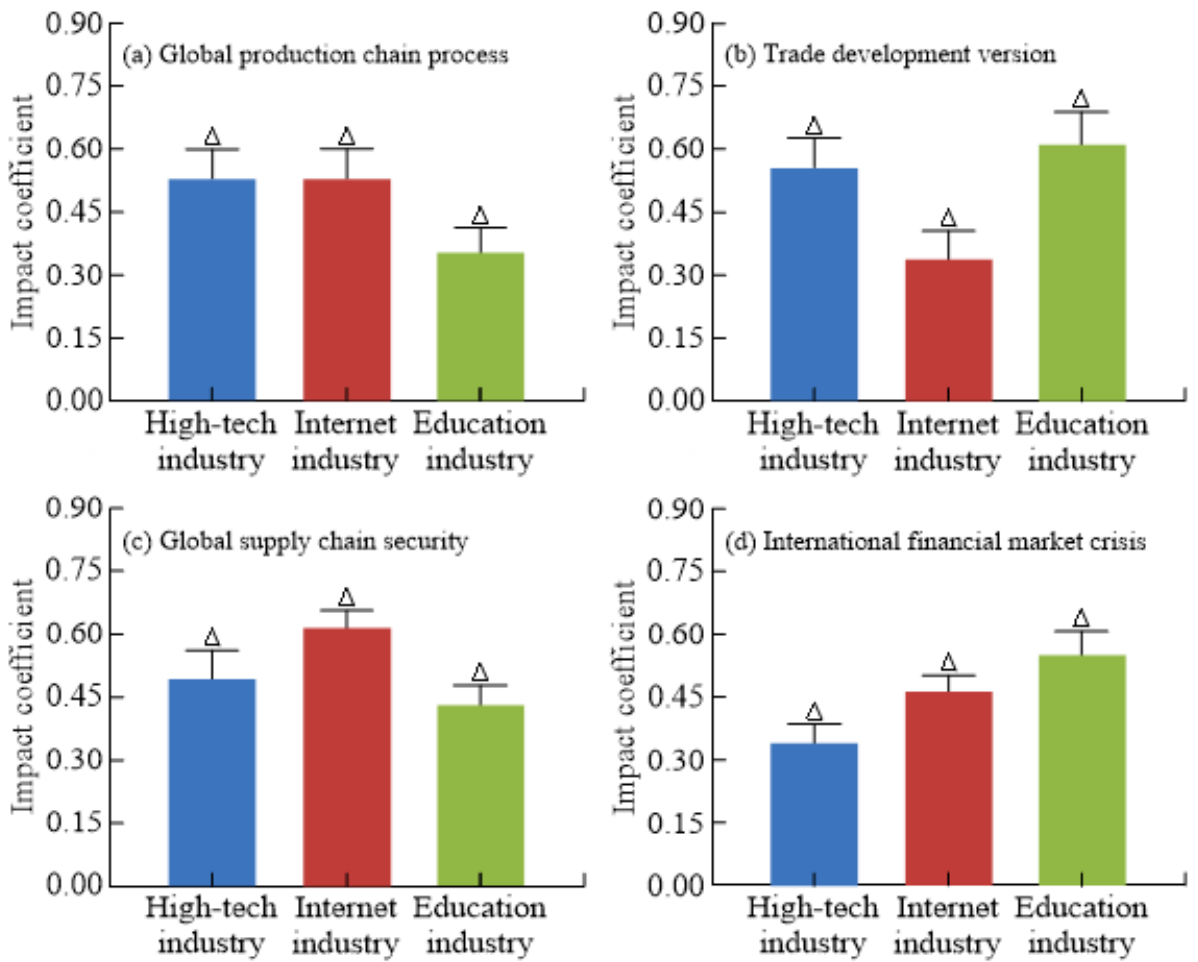

which has an adverse impact on the global allocation of production factors; although these policies have a certain degree of prevention and control of the COVID-19 epidemic in their own countries. However, it has a great destructive effect on the global flow and market allocation of production factors and commodities (Singh et al., 2020). In the theoretical discussion of the relationship between the COVID-19 epidemic and economic globalization, many scholars discuss the impact of the COVID-19 epidemic on economic globalization from different perspectives. The global pandemic will definitely have an important and far-reaching impact on the world economic development. The overall spread of the COVID-19 epidemic has damaged the regional ecosystem of global economic development; the exogenous nature of the damage caused by the COVID-19 epidemic has damaged the dynamic ecosystem of global economic development. The prevention and control of the COVID-19 epidemic has not only directly affected the speed of the development of transnational trade, but also changed the structure of world trade regions and industries, and reshaped the future development of world trade. The in-depth development of the COVID-19 epidemic globally has not only made the original economic growth model of various countries unsustainable, but also made it difficult for countries' new economic growth methods to achieve practical results in the short term (Figure 6).

For small, medium and micro enterprises in the upper reaches of the industrial chain, the epidemic will cause soaring raw material import costs and shortages of components, making production unsustainable. While for small, medium and micro enterprises in the downstream of the industrial chain, the epidemic will cause companies to face a series of problems such as slow sales of products and sharp decline in profits. Compared with large enterprises, state-owned or joint ventures, small, medium and micro private enterprises have inherent deficiencies in their anti-risk capabilities and 
financing capabilities (Morrar et al., 2019). Therefore, it is necessary to increase support for small, medium and micro enterprises to help them overcome difficulties and improve the economy and guarantee employment. Since international finance, many countries have mainly relied on quantitative easing and ultra-low interest rates to boost their economies, leading to asset price bubbles, rising debt leverage, widening of the wealth gap among residents, social tearing, and prevalence of trade protectionism. Among them, high corporate debt leverage has led to the stock market bubble. Although some countries have made outstanding achievements and made good achievements in fighting the epidemic and resuming production, they are still due to the high degree of global financial system connection and all-weather risk parity funds in the short term. The boost of factors, coupled with the panic in the global financial market triggered by the sharp fall in the stock market in the short term, will definitely have a short-term impact on the financial market.

Since the outbreak happened just during some holidays, the holiday effects of consumption of goods and services in previous years have been severely suppressed. Unlike commodity consumption that will quickly make up for after the epidemic subsides, some service consumption losses are irreversible, and the impact is relatively long. Affected by factors such as traffic control, delays in resuming work, employment difficulties, and weakened terminal demand, industrial production and construction will also be impacted, and downstream industries close to terminal consumption will be more affected in the short term, and will gradually move along the industrial chain. In terms of exports, due to the temporary inability to recover the production capacity of some industries, the production capacity of a considerable number of export-oriented enterprises, especially small and medium-sized enterprises, has been severely suppressed (Khatwani \& Srivastava, 2018). The sharp decrease in income and the superposition of rigid expenditures have made it difficult for some companies to sustain themselves. Companies in the upstream of the industry chain are still at risk of being replaced by competitors and may go bankrupt due to the loss of customers and the market. At the same time, business operations involve multiple stakeholders such as upstream and downstream companies, employees, tenants, creditors, etc. The ability to pay due to the epidemic has generally declined or even lost, which will trigger a series of chains such as defaults, claims, and reductions in corporate credit, but the existing insurance still has the insufficiency of insurance liability and the difficulty in fulfilling insurance claims.

\subsection{Economic Globalization Pattern}

When demand rebounds, manufacturing companies can often find a way to make up most of the loss in sales, but it is difficult for the service industry to recover the consumption that may occur in the elapsed time. Coupled with the continued impact of the epidemic on people's lifestyles, it is estimated that the demand for service industries such as tourism will hardly rebound significantly. Therefore, it will be a slower process to return to the level before the epidemic. Although retail and manufacturing have been hit hard, it may be quite different in different formats. The development of the offline retail industry has undoubtedly suffered setbacks, but the online retail industry has taken advantage of the epidemic to obtain further development opportunities, and a series of new consumption, new products, new formats and new models have emerged, which has played a role in ensuring stability and supply (Figure 7). Under the continuation of the epidemic, the financial market may still fluctuate and fall, but the volatility will be further differentiated by industry and function indirectly provide support and guarantee for the manufacturing industry. After the epidemic is completely over, the financial market will definitely undergo tremendous changes. First of all, negative interest rates will fundamentally change the market's risk premium, risk pricing, and market pricing; the market rules will change, and what will change with it is the link between the entire assets. Secondly, for traditional banks, the pace of digital transformation will be further accelerated.

Economic exogenous shocks can be roughly divided into demand shocks and supply shocks. The real business cycle theory school believes that supply shocks are the main cause of economic fluctuations, and the corresponding economic fluctuations are persistent. Although different schools 
Figure 7. Impact coefficient variations with COVID-19 epidemic duration in optimistic (a) and pessimistic (b) situation
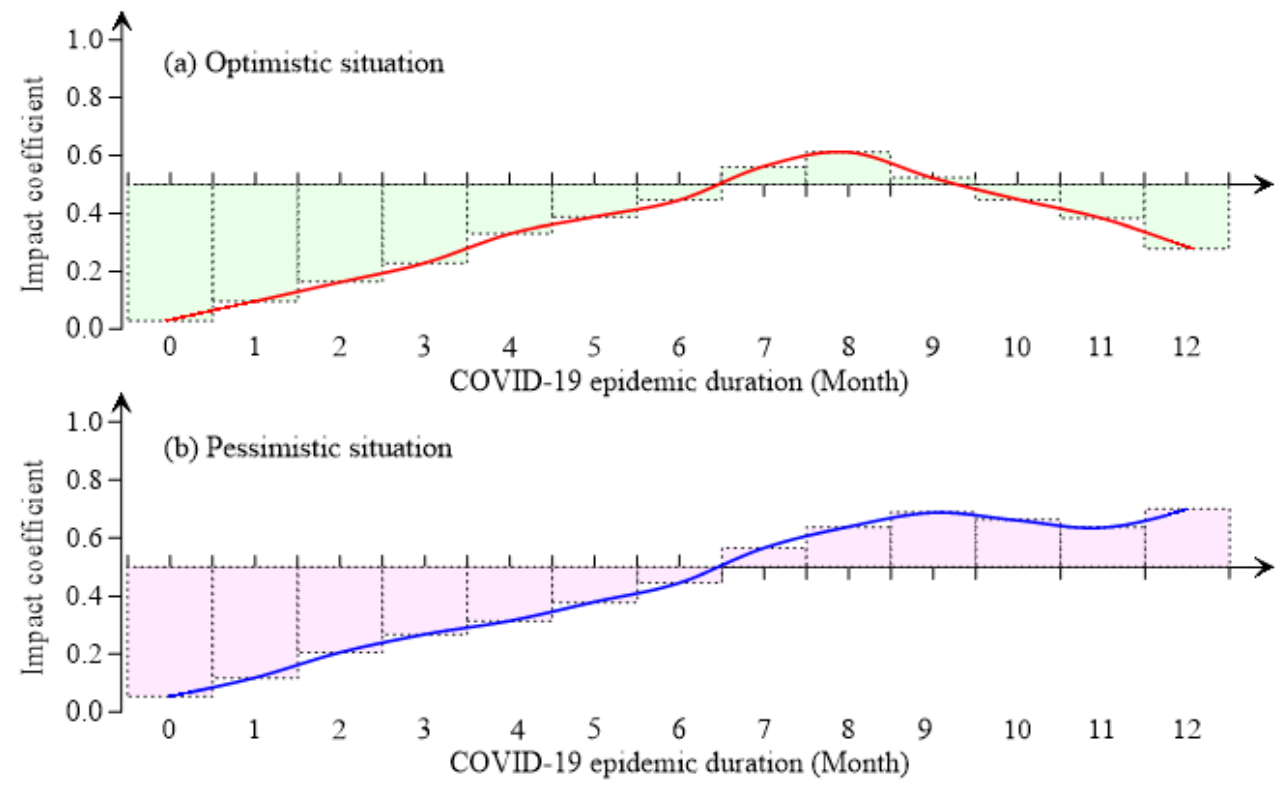

of thought have great controversy over the main causes of economic fluctuations, they all agree that supply shocks have long-term effects on economic output, while demand shocks have short-term effects on economic output. Many scholars decompose economic shocks into demand shocks and supply shocks, and empirically analyze the impact of different shocks on the economy, so as to provide empirical support for the above conclusions. The demand shock caused by the epidemic will not affect economic output, and both economic equilibrium output and demand will be restored. On the supply side, changes in the long-term economic output level depend on whether the epidemic has a substantial impact on labor supply, capital accumulation, and factor productivity (Figure 8). Theoretically, when the economy is subject to both a demand shock and a supply shock, if the longterm supply curve is affected by the shock and shifts to the left, the shock on the demand side of the economy will not be restored. In the real economy, with the continuous growth of investment and technological progress, the potential output of the economy is also continuously increasing, that is, the long-term supply curve continues to shift to the right (de Jesus et al., 2020).

The first-stage administrative economic recovery, led by the promotion of resumption of work and production and marked by supply-side restoration, has been completed, but the second-stage deep market-based recovery, led by demand expansion and marked by economic cycle restoration, has just begun. Resident consumption and corporate investment continue to rebound, but the speed of recovery is getting slower and slower than the speed of supply recovery. In the process of normalization of economic operation, the gap between supply and demand has not narrowed, but has continued to expand and this has led to the bottleneck constraint of the normalization of economic cycles. Supplyside factors such as the supply chain of the industrial chain have turned to demand-side factors such as insufficient market demand and lack of orders, which fully shows that after the completion of the supply-driven economic recovery phase of the first phase, the performance of the new phase of economic recovery will largely depend on the demand side (Mou et al., 2020). Under the impact of the epidemic, the behavior patterns of various market entities have undergone drastic adjustments. Deterioration of income and employment expectations of residents suppresses consumer demand, high uncertainty suppresses investment demand, and the accelerated spread of overseas epidemics 
Figure 8. Impact factor (a) of COVID-19 epidemic on three typical economic fields and their loss factors (b) in optimistic and pessimistic situations
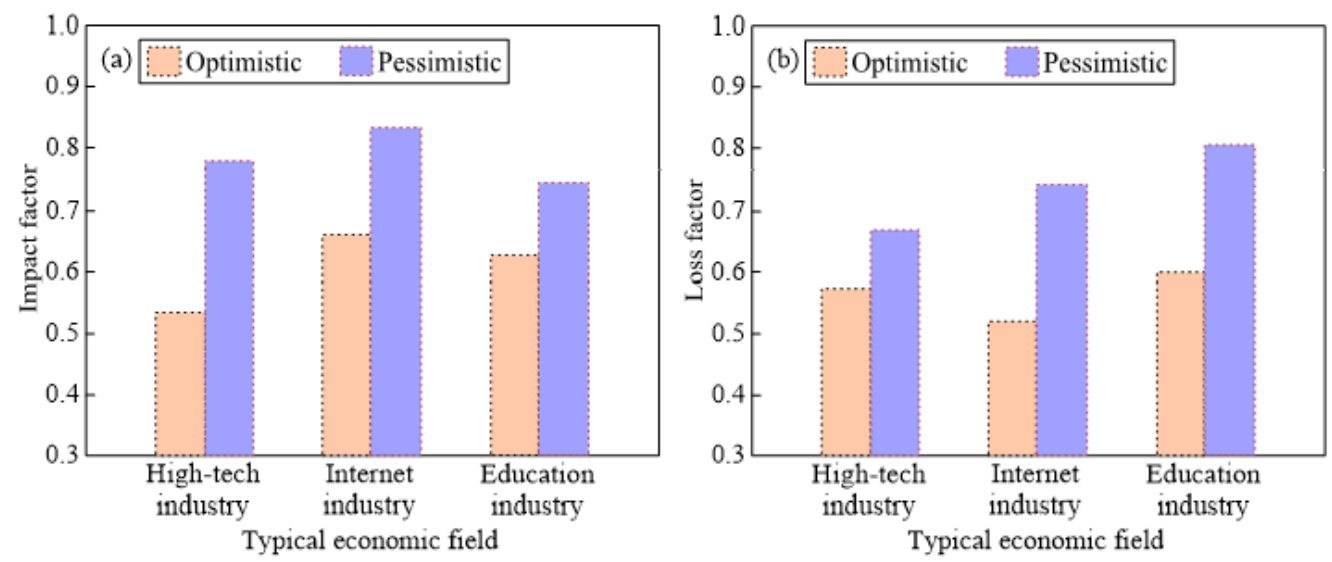

suppresses export demand, which may lead to conservative consumer behavior, corporate investment behavior, and the transformation and upgrading of export-oriented enterprises. This restricts the pace of short-term economic recovery and the quality of medium and long-term economic development.

\section{CONCLUSION}

This paper analyzed the impact of the COVID-19 epidemic on the global production chain process and trade development version, explored the impact of the COVID-19 epidemic on global supply chain security and international financial market crisis, and discussed the economic policy support system and the economic globalization pattern in the post-epidemic era. The COVID-19 epidemic is a major external shock that has affected the trend of the world economic structure since economic globalization. On the one hand, the epidemic may cause the world to experience the worst economic recession since the great depression; on the other hand, the impact of the epidemic is intensifying the structural reshuffle between countries, accelerating the localization, regionalization, and decentralization of the global supply chain and industrial chain. When demand rebounds, manufacturing companies can often find a way to make up most of the loss in sales, but it is difficult for the service industry to recover the consumption that may occur in the elapsed time. In some areas, enterprises need to have the relevant prevention and control equipment and measures reviewed by the government department, and the relevant government department has issued a work permit before they can resume production. In the context of the global pandemic of the COVID-19 epidemic, international trade through cross-border e-commerce and even global digital trade have obvious practical significance. In the short term, the commerce can help meet the cross-border shopping needs of domestic consumers, help domestic export companies match the needs of overseas markets, and restore the normal operation of all links in the trade chain. In the long run, global digital trade will help to improve the operational efficiency of the entire chain of cross-border trade, to cultivate the advantages of enterprises to participate in international competition, and to enhance the foreign trade industry's ability to respond to various risks such as the epidemic. The study results of this paper provide a reference for further researches on the impact of the impact of the COVID-19 epidemic on the global trade economy based on big data analysis. 


\section{ACKNOWLEDGMENT}

The Key Research Project of Philosophy and Social Sciences of the Ministry of Education, The Research on the Mass Media and Communication of Social Thoughts in 40 Years of Reform and Opening-up, Project No. 18JZD022. 


\section{REFERENCES}

Ahluwalia, P., \& Merhi, M. I. (2020). Understanding country level adoption of e-commerce: A theoretical model including technological, institutional, and cultural factors. Journal of Global Information Management, 28(1), 1-22. doi:10.4018/JGIM.2020010101

Bhoring, S. K. (2020). Impact of coronavirus on Indian economy. International Journal for Research in Applied Science and Engineering Technology, 8(5), 1332-1339. doi:10.22214/ijraset.2020.5212

Cacciapaglia, G., Cot, C., \& Sannino, F. (2020). Second wave COVID-19 pandemics in Europe: A temporal playbook. Scientific Reports, 10(1), 15514. doi:10.1038/s41598-020-72611-5 PMID:32968181

Celik, B., Ozden, K., \& Dane, S. (2020). The effects of COVID-19 pandemic outbreak on the household economy. Journal of Research in Medical and Dental Science, 8(4), 51-56.

Cunningham, S., \& Scarlata, A. (2020). New forms of internationalisation? The impact of Netflix in Australia. Media International Australia, 177(1), 149-164. doi:10.1177/1329878X20941173

de Jesus, D. S. V., Kamlot, D., \& Dubeux, V. J. C. (2020). Innovation in the 'new normal' interactions, the urban space, and the low touch economy: The case of rio de janeiro in the context of the COVID-19 pandemic. International Journal of Social Science Studies, 8(5), 17-27. doi:10.11114/ijsss.v8i5.4900

Derevyankina, E. S., \& Yankovskaya, D. G. (2020). The impact of Covid-19 on supply chain management and global economy development. International Journal of Supply Chain Management, 9(4), 765-774.

Evenett, S. J. (2020). Sicken thy neighbour: The initial trade policy response to COVID-19. World Economy, 43(4), 828-839. doi:10.1111/twec.12954

Fabisiak, L. (2018). Web service usability analysis based on user preferences. Journal of Organizational and End User Computing, 30(4), 1-13. doi:10.4018/JOEUC.2018100101

Halawani, F. M., Soh, P. C.-H., \& Halawani, Y. M. (2020). Social media utilisation and business performance of hotels in Lebanon: Exploring the moderating effects of hotel classification. Journal of Global Information Management, 28(3), 58-76. doi:10.4018/JGIM.2020070104

Hart, O. E., \& Halden, R. U. (2020). Computational analysis of SARS-CoV-2/COVID-19 surveillance by wastewater-based epidemiology locally and globally: Feasibility, economy, opportunities and challenges. The Science of the Total Environment, 730, 138875-138875. doi:10.1016/j.scitotenv.2020.138875 PMID:32371231

Jones, E. (2020). COVID-19 and the EU economy: Try again, fail better. Survival, 62(4), 81-100. doi:10.108 $0 / 00396338.2020 .1792124$

Khan, I. U., Hameed, Z., \& Khan, S. U. (2017). Understanding online banking adoption in a developing country: UTAUT2 with cultural moderators. Journal of Global Information Management, 25(1), 43-65. doi:10.4018/ JGIM.2017010103

Khatwani, G., \& Srivastava, P. R. (2018). Impact of Information Technology on Information Search Channel Selection for Consumers. Journal of Organizational and End User Computing, 30(3), 63-80.

Kim, H. (2019). Investigating the mediating role of social networking service usage on the big five personality traits and on the job satisfaction of Korean workers. Journal of Organizational and End User Computing, 31(1), 110-123. doi:10.4018/JOEUC.2019010106

Matthijs, M. (2020). Lessons and learnings from a decade of EU crises. Journal of European Public Policy, 27(8), 1127-1136. doi:10.1080/13501763.2020.1787489

McEwan, K., Marchand, L., Shang, M., \& Bucknell, D. (2020). Potential implications of COVID-19 on the Canadian pork industry. Canadian Journal of Agricultural Economics-Revue Canadienne D Agroeconomie, 68(2), 201-206.

Morrar, R., Abdeljawad, I., Jabr, S., Kisa, A., \& Younis, M. Z. (2019). The role of information and communications technology (ICT) in enhancing service sector productivity in Palestine: An international perspective. Journal of Global Information Management, 27(1), 47-65. doi:10.4018/JGIM.2019010103 
Mou, J., Cui, Y., \& Kurcz, K. (2020). Trust, risk and alternative website quality in B-buyer acceptance of crossborder e-commerce. Journal of Global Information Management, 28(1), 167-188. doi:10.4018/JGIM.2020010109

Raposo, V. L. (2020). Can China's "standard of care" for COVID-19 be replicated in Europe? Journal of Medical Ethics, 46(7), 451-454. doi:10.1136/medethics-2020-106210 PMID:32424062

Sidhu, G. S., Rai, J. S., Khaira, K. S., \& Kaur, S. (2020). The impact of Covid-19 pandemic on different sectors of the Indian economy: A Descriptive Study. International Journal of Economics and Financial Issues, 10(5), 113-120. doi:10.32479/ijefi.10461

Singh, A. K., Upadhyaya, A., Kumari, S., Sundaram, P. K., \& Jeet, P. (2020). Role of agriculture in making India \$5 trillion economy under corona pandemic circumstance. Journal of Animal Science, 7(2), 54-58.

Singh, P., \& Agrawal, R. (2018). A customer centric best connected channel model for heterogeneous and IoT networks. Journal of Organizational and End User Computing, 30(4), 32-50. doi:10.4018/JOEUC.2018100103

Wei, C. L., \& Ho, C. T. (2019). Exploring signalling roles of service providers' reputation and competence in influencing perceptions of service quality and outsourcing intentions. Journal of Organizational and End User Computing, 31(1), 86-109. doi:10.4018/JOEUC.2019010105

Wei, X. (2020). Transnational capital and the trend of global interactions. International Critical Thought, 10(2), 251-262. doi:10.1080/21598282.2020.1783694 